\title{
IRIS Recognition using Hough Transform
}

\author{
C. Rajabhushnam,. B Sundar Raj, Sri vidhya
}

\begin{abstract}
In most iris identification systems, the complete image acquires constraints are understood. These Constrain include near-infrared (NIR) illumination to release the iris texture and close distance from the capturing device. In recent advances to different illumination technologies introduced in images captured in the environment. This environment includes a visible wavelength $(\mathrm{VW})$ light source at-a-distance over the close distance from the capturing device. For accurate Iris identification at-a-distance, eye images require improvement of effective strategies, while setting the light source at a distance from the planar view of the iris. Effectively performing feature extraction technique for Near-Infrared and Visible wavelength images, that were collected in an uncontrolled stage. The identification of iris accuracy on the publicly available databases was then measured. This paper presents a preprocessing of Iris Recognition using Hough Transform (HT) for Iris Area of interest (AOI) and rubber-sheeting the model captured using linear stretching and rotation for normalization. The HT is used to filter and contrast stretch the iris regions from multispectral iris images. A basic purpose of this research is to envelop a design and implement IRIS-recognition at a distance (IAAD) by adopting a frequency and wavelength-based Hough transform for accurate feature selection [1][2]. The proposed method is described as follows: Initially, the input iris image will be subjected to pre-processing while extracting features with differences from local extrema and maxima conditions, using a regular shape filling Hough transform [3][4]. The iris localization and detection consists of a hill climbing segmentation approach that is based on geometric shape Hough measure. Proposed in comparison to the contemporary.
\end{abstract}

Keywords:. Hough Transform (HT), Iris Segmentation, Iris Normalization, Enhancement

\section{INTRODUCTION}

In a biometrics system, Iris Identification of people based on individual patterns within a small circular band an area near the pupil of the eye. Which consist of pattern recognition technique iris patterns are more secure and well grounded. It is one of the best recognition techniques which images can be taken from human eyes free from restrictions like special light sources [5][6]. There is some Iris recognition mechanism is: [14],[16], [18]

\section{A. Iris Segmentation}

B. Iris Normalization

\footnotetext{
Revised Manuscript Received on July 22, 2019

C. Rajabhushnam, Department of Computer Science and Engineering, Bharath Institute of Higher education and research, Chennai , India

B Sundar Raj, Department of Computer Science and Engineering, Bharath Institute of Higher education and research, Chennai , India

Sri vidhya, Department of Computer Science and Engineering, Bharath Institute of Higher education and research, Chennai, India
}

\section{C.Image Enhancement}

\section{A. Iris Segmentation}

It is a crucial method in the iris identification procedure It is based on original characteristics of iris[8]. To localize area of interest from iris, involves applying geometric constraints to the patch. Doing so involves three operations -

- Binary dilate localization in inward region

- Binary erode localization in outward region

- Binary filter operation on features surrounding the eye

- Inward feature space localization

For delineating in the inward feature space, the location of the reflection on the lens (behind the pupil) is required. The plotted image of an eye analyzed the gray levels histogram for the eye lens reflection image, an adaptive cut-off value $T$ is computed as intensity saturation value corresponding to the local maxima gradient within the histogram. Intensity saturation values in the eye lens image, lesser than the computed value of $\mathrm{T}$ are updated to 0 (black) and greater than computed value of $\mathrm{T}$ is updated to 255 (white), as: [1],[3],[5]

Here, $B(i, j)$ is defined as the brightness value at eye lens location $(i, j), P(x, y)$ is the linearly transformed digital number value and $\mathrm{T}$ represents boundary value. To filter the digital numbers situated outside the eye lens reflected area, morphological processing is required. [19],[21],[23]

Through this process conversion of the gray image is converted into the binary image, after localization of iris to find out the Normalized image Daugman's rubber sheet model is used[9][10]. 


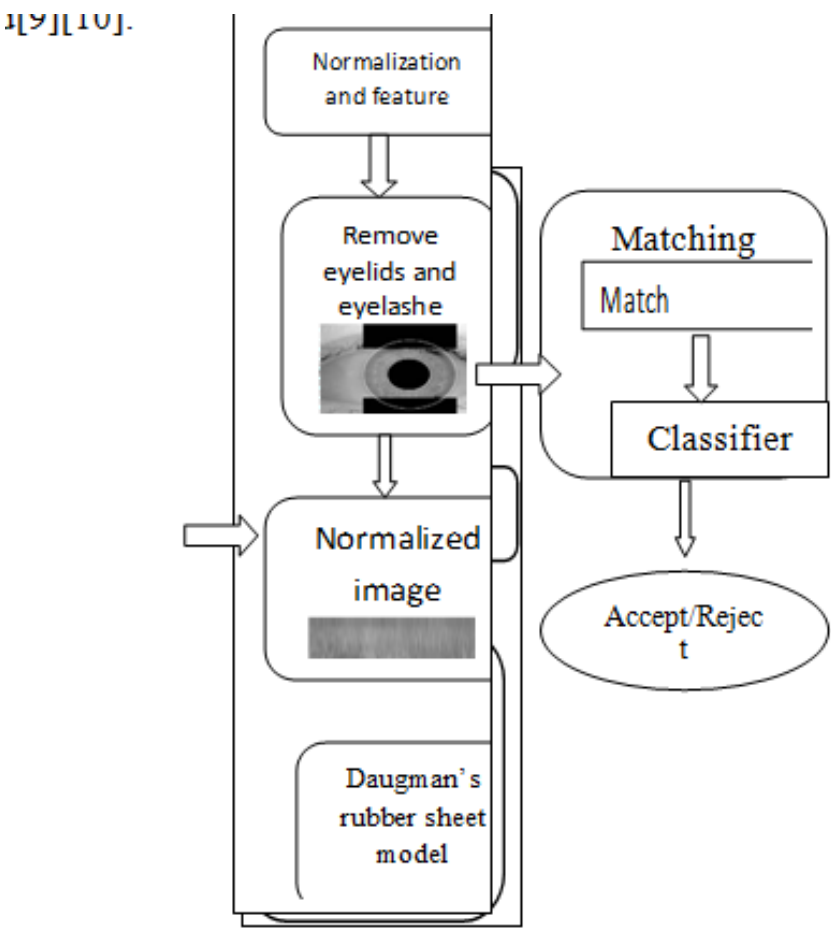

Fig 2, Iris Localization using improved Hough transforms.

\section{Outer boundary localization :}

To localize the outer boundary, require more concentration due to its complexity, recently different techniques used to find iris outer boundary: 1) Finding Circle; 2) Detection of the edge by using Hough transform 3) Curve fitting. Hereby examination of the restriction of the above three localization methods based on Hough transform determines - First, find all the points for an outer boundary and detect the edge using

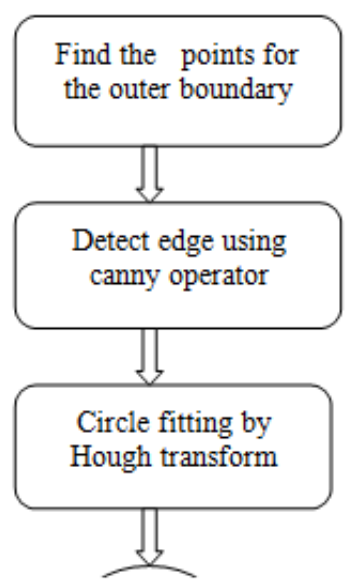

Figure 3" structure of iris outer boundary localization"

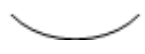

\section{Eyelids and eyelashes detection.}

In iris sensitivity recognition system, edge detection for eyelids and eyelashes that surround the eyes is the most important characteristics, which affect computation of detecting or Iris-lens normalization: The normalization step aids in computing the differences in adjoining regions to varying iris sizes, and improves the precision of matching. We can find the circle noise an area in the iris image after applying a circular Hough transform. The linear wavelength / frequency-based Hough sliding window is a biological imaging algorithm that can be employed to compute the boundaries of localized geometric space filling curves, such as lines and circles, inherent in an pixel coordinate. The basic Hough sliding window transform, translates the location of a shape in $\mathrm{x}, \mathrm{y}$-planar surface to the parameterized domain. Then the proposed geometric shape indicator of a Circle-Hough area operation is applied to decrease the radii and observed dimensions of the eye lens aperture coordinates [7]. [32],[34],[36]

\section{B.Normalization}

Iris image is captured by single person's eye. The captured iris picture is segmented with the help of polarization in the feature localization procedure. [38],[40],[42] This step is necessary for applying first order differentiation. With dimensional unpredictability in eye varying images due to contrast equalization of iris, arising from pupil dilation with different point sources of light. Error measures arise from varying imaging parameter distance, rotation of point source, head tilt, and rotary motion of the eye. The iris-factorization procedure will result in the projection onto an area that has the same continuous feature space. Now, the two feature vectors of the same iris with dissimilarity present in the adjoining area of interest, will have areal features (continuous lines and circles) at the same spatial location [11].

\section{E.Iris Daugman's rubber sheet model}

Normalization in Daugman's technique is time variant in identification of applications and Classification. The normalization procedure is found with other method as compared to Daugman's abstraction. In this procedure, feature space is normalized and projected with matching time parameters[10][13].

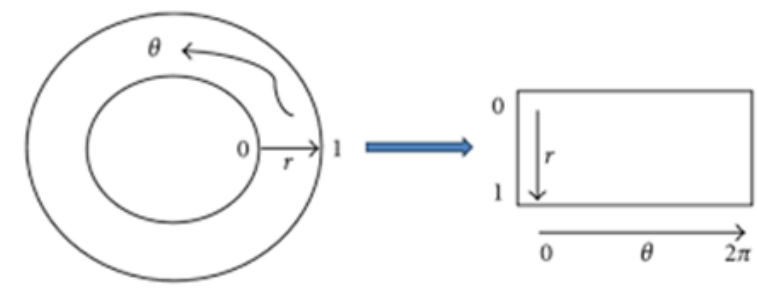

Figure 4" structure of iris outer boundary localization"

\section{FEATURE EXTRACTION}

Feature demarcation and extraction is an important step in recognition systems (IAAD). The required texture patterns are extracted from the entire iris image [16]. A typical iris identification technique normally consists of some modules as below: [8],[ 10] ,[12]

1. pre-processing technique

2. Iris pattern recognition for feature extraction it.

3. Image classification for 
measuring accuracy.

In this technique first segmentation then Normalization and the matching of patterns used for recognition purpose. Color image is converted into gray then gray into binary. Then eye location is identified that detects the approximate center of the pupil. Then find an inner feature boundary of an iris and it abstracts the predefined ratio of identification $[14][15]$..

\section{CONCLUSION}

The salient features in this study provide a proper methodology of steps and scope for future research in "Iris preprocessing using proposed Hough transform and Daugman's rubber sheet model". The results from this research affirm the effective approach for iris recognition. In our proposed algorithm for segmentation of geometric shape and selection of pupillary edges, it is determined that the approximation of eye coordinates in the location and corresponding area of interest, clips in a region. The spatially invariant feature transform produces an ellipse that is produced by space filling circular Hough technique in the edge boundaries within an accurate area of interest (AOI). Iris normalization means to reduce space-time differences between iris scan slices, occuring in rubber sheet projection. [14], [ 16], [18].

\section{ACKNOWLEDGMENT}

The authors want to thank Bharath Institute of Higher Education and Research, Selaiyur, Chennai. Also thanks to NBN Sinhgad School of engineering, Ambegaon, Pune. Institute of Automation and Chinese Academy of Sciences for access to CASIA data set.

\section{REFERENCES}

[1] Kumarave A., Rangarajan K.,Algorithm for automaton specification for exploring dynamic labyrinths,Indian Journal of Science and Technology,V-6,I-SUPPL5,PP-4554-4559,Y-2013

[2] P. Kavitha, S. Prabakaran "A Novel Hybrid Segmentation Method with Particle Swarm Optimization and Fuzzy C-Mean Based On Partitioning the Image for Detecting Lung Cancer" International Journal of Engineering and Advanced Technology (IJEAT) ISSN: 2249-8958, Volume-8 Issue-5, June 2019

[3] Kumaravel A., Meetei O.N.,An application of non-uniform cellular automata for efficient cryptography,2013 IEEE Conference on Information and Communication Technologies, ICT 2013,V-,I-,PP-1200-1205,Y-2013

[4] Kumarave A., Rangarajan K.,Routing alogrithm over semi-regular tessellations,2013 IEEE Conference on Information and Communication Technologies, ICT 2013,V-,I-,PP-1180-1184,Y-2013

[5] P. Kavitha, S. Prabakaran "Designing a Feature Vector for Statistica Texture Analysis of Brain Tumor" International Journal of Engineering and Advanced Technology (IJEAT) ISSN: 2249-8958, Volume-8 Issue-5, June 2019

[6] Dutta P., Kumaravel A.,A novel approach to trust based identification of leaders in social networks,Indian Journal of Science and Technology,V-9,I-10,PP--,Y-2016

[7] Kumaravel A., Dutta P.,Application of Pca for context selection for collaborative filtering,Middle - East Journal of Scientific Research,V-20,I-1,PP-88-93,Y-2014

[8] Kumaravel A., Rangarajan K.,Constructing an automaton for exploring dynamic labyrinths,2012 International Conference on

Radar, Communication and Computing, ICRCC 2012,V-,I-,PP-161-165,Y-2012

[9] P. Kavitha, S. Prabakaran "Adaptive Bilateral Filter for Multi-Resolution in Brain Tumor Recognition" International Journal of Innovative Technology and Exploring Engineering (IJITEE) ISSN: 2278-3075, Volume-8 Issue-8 June, 2019

[10] Kumaravel A.,Comparison of two multi-classification approaches for detecting network attacks, World Applied Sciences Journal,V-27,I-11,PP-1461-1465,Y-2013

[11] Tariq J., Kumaravel A.,Construction of cellular automata over hexagonal and triangular tessellations for path planning of multi-robots,2016 IEEE International Conference on Computational Intelligence and Computing Research, ICCIC 2016,V-,I-,PP--,Y-2017

[12] Sudha M., Kumaravel A.,Analysis and measurement of wave guides using poisson method,Indonesian Journal of Electrical Engineering and Computer Science,V-8,I-2,PP-546-548,Y-2017

[13] Ayyappan G., Nalini C., Kumaravel A.,Various approaches of knowledge transfer in academic social network,International Journal of Engineering and Technology,V-,I-,PP-2791-2794,Y-2017

[14] Kaliyamurthie, K.P., Sivaraman, K., Ramesh, S. Imposing patient data privacy in wireless medical sensor networks through homomorphic cryptosystems 2016, Journal of Chemical and Pharmaceutical Sciences 92.

[15] Kaliyamurthie, K.P., Balasubramanian, P.C. An approach to multi secure to historical malformed documents using integer ripple transfiguration 2016 Journal of Chemical and Pharmaceutical Sciences 92.

[16] A.Sangeetha,C.Nalini,"Semantic Ranking based on keywords extractions in the web", International Journal of Engineering \& Technology, 7 (2.6) (2018) 290-292

[17] S.V.GayathiriDevi,C.Nalini,N.Kumar,"An efficient software verification using multi-layered software verification tool "International Journal of Engineering \& Technology, 7(2.21)2018 454-457

[18] C.Nalini,ShwtambariKharabe,"A Comparative Study On Different Techniques Used For Finger - Vein Authentication", International Journal Of Pure And Applied Mathematics, Volume 116 No. 8 2017, 327-333, Issn: 1314-3395

[19] M.S. Vivekanandan and Dr. C. Rajabhushanam, "Enabling Privacy Protection and Content Assurance in Geo-Social Networks", International Journal of Innovative Research in Management, Engineering and Technology, Vol 3, Issue 4, pp. 49-55, April 2018.

[20] Dr. C. Rajabhushanam, V. Karthik, and G. Vivek, "Elasticity in Cloud Computing", International Journal of Innovative Research in Management, Engineering and Technology, Vol 3, Issue 4, pp. 104-111, April 2018.

[21] K. Rangaswamy and Dr. C. Rajabhushanamc, "CCN-Based Congestion Control Mechanism In Dynamic Networks", International Journal of Innovative Research in Management, Engineering and Technology, Vol 3, Issue 4, pp. 117-119, April 2018.

[22] Kavitha, R., Nedunchelian, R., "Domain-specific Search engine optimization using healthcare ontology and a neural network backpropagation approach", 2017, Research Journal of Biotechnology, Special Issue 2:157-166

[23] Kavitha, G., Kavitha, R., "An analysis to improve throughput of high-power hubs in mobile ad hoc network" , 2016, Journal of Chemical and Pharmaceutical Sciences, Vol-9, Issue-2: 361-363

[24] Kavitha, G., Kavitha, R., "Dipping interference to supplement throughput in MANET" , 2016, Journal of Chemical and Pharmaceutical Sciences, Vol-9, Issue-2: 357-360

[25] Michael, G., Chandrasekar, A.,'Leader election based malicious detection and response system in MANET using mechanism design approach", Journal of Chemical and Pharmaceutical Sciences(JCPS) Volume 9 Issue 2, April - June 2016

[26] Michael, G., Chandrasekar, A.,"Modeling of detection of camouflaging worm using epidemic dynamic model and power spectral density", Journal of Chemical and Pharmaceutical Sciences(JCPS) Volume 9 Issue 2, April - June 2016.

[27] Pothumani, S., Sriram, M., Sridhar, J., Arul Selvan, G., Secure mobile agents communication on intranet,Journal of Chemical and Pharmaceutical Sciences, volume 9, Issue 3, Pg No S32-S35, 2016

[28] Pothumani, S., Sriram, M., Sridhar, Various schemes for database encryption-a 
survey, Journal of Chemical and Pharmaceutical Sciences, volume 9, Issue 3, Pg NoS103-S106, 2016

[29] Pothumani, S., Sriram, M., Sridhar, A novel economic framework for cloud and grid computing, Journal of Chemical and Pharmaceutical Sciences, volume 9, Issue 3, Pg No S29-S31, 2016

[30] Priya, N., Sridhar, J., Sriram, M. "Ecommerce Transaction Security Challenges and Prevention Methods- New Approach” 2016 ,Journal of Chemical and Pharmaceutical Sciences, JCPS Volume 9 Issue 3.page no:S66-S68

[31] Priya, N.,Sridhar,J.,Sriram, M."Vehicular cloud computing security issues and solutions" Journal of Chemical and Pharmaceutical Sciences(JCPS) Volume 9 Issue 2, April - June 2016

[32] Priya, N., Sridhar, J., Sriram, M. "Mobile large data storage security in cloud computing environment-a new approach" JCPS Volume 9 Issue 2. April - June 2016

[33] Anuradha.C, Khanna.V, "Improving network performance and security in WSN using decentralized hypothesis testing "Journal of Chemical and Pharmaceutical Sciences(JCPS) Volume 9 Issue 2, April - June 2016.

[34] Anuradha.C, Khanna.V, "A novel gsm based control for e-devices" Journal of Chemical and Pharmaceutical Sciences(JCPS) Volume 9 Issue 2, April - June 2016.

[35] Anuradha.C, Khanna.V, "Secured privacy preserving sharing and data integration in mobile web environments " Journal of Chemical and Pharmaceutical Sciences(JCPS) Volume 9 Issue 2, April - June 2016.

[36] Sundarraj, B., Kaliyamurthie, K.P. Social network analysis for decisive the ultimate classification from the ensemble to boos accuracy rates 2016 International Journal of Pharmacy and Technology 8

[37] Sundarraj, B., Kaliyamurthie, K.P. A content-based spam filtering approach victimisation artificial neural networks 2016 International Journal of Pharmacy and Technology 83.

[38] Sundarraj, B., Kaliyamurthie, K.P. Remote sensing imaging for satellite image segmentation 2016 International Journal of Pharmacy and Technology 83 .

[39] Sivaraman, K., Senthil, M. Intuitive driver proxy control using artificial intelligence 2016 International Journal of Pharmacy and Technology 84.

[40] Sivaraman, K., Kaliyamurthie, K.P. Cloud computing in mobile technology 2016 Journal of Chemical and Pharmaceutical Sciences 92.

[41] Sivaraman, K., Khanna, V. Implementation of an extension for browser to detect vulnerable elements on web pages and avoid click jacking 2016 Journal of Chemical and Pharmaceutical Sciences 92 .

\section{AUTHORS PROFILE}

C. Rajabhushnam, Associate Professor, Department of Computer Science \& Engineering, Bharath Institute of Higher Education and Research, Chennai, India

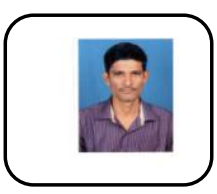

B. Sundar Raj Assistant Professor, Department of Computer Science \& Engineering, Bharath Institute of Higher Education and Research, Chennai, India 